\title{
THE METAMORPHOSIS OF THE ANTHOMEDUSA, POLYORCHIS KARAFUTOENSIS KISHINOUYE
}

$\operatorname{AUTHOR}(S)$ :

Nagao, Zen

\section{CITATION:}

Nagao, Zen. THE METAMORPHOSIS OF THE ANTHOMEDUSA, POLYORCHIS

KARAFUTOENSIS KISHINOUYE. PUBLICATIONS OF THE SETO MARINE BIOLOGICAL LABORATORY 1970, 18(1): 21-35

ISSUE DATE:

1970-09-16

URL:

http://hdl.handle.net/2433/175622

RIGHT: 


\title{
THE METAMORPHOSIS OF THE ANTHOMEDUSA, POLYORCHIS KARAFUTOENSIS KISHINOUYE
}

\author{
ZEN NAGAO \\ Laboratory of Science Education, Kushiro Branch, Hokkaido University \\ of Education, Kushiro, Hokkaido, Japan
}

With 11 Text-figures

One of the highest Anthomedusa, Polyorchis karafutoensis was first described by Kishinouye (1910) from Sakhalin. Since then the medusa was sometimes reported from the southern coast and the eastern lagoon of Sakhalin and the eastern part of Hokkaido, Japan by Uahida (1925, 1927, 1940). However, its life history remains mostly unknown, as also in other members of the genus Polyorchis except for the fragmental records of the medusan development in $P$. penicillatus by Fewkes (1889) and Foerster (1923), in P. karafutoensis by UchIDA (1927) and in P. montereyensis by Skogsberg (1948).

In Akkeshi Bay Polyorchis karafutoensis is commonly found from middle April to late July. The early development of this species was previously reported by the author (NAGAO, 1963). In the present paper the metamorphosis and the growth in the medusan stage are dealt with. The medusae were collected in Akkeshi Bay and in Akkeshi Lake which is a lagoon and is directly connected with the bay (cf. Uchida et al., 1963). The medusae were collected by surface tow every week on the average during April - July in 1963 and 1965. In the later season when the medusae grow larger they were scooped with a net. Umbrellar form, ocelli, size and other living characters of the medusae were recorded before preservation.

Before proceeding further the author wishes to express his sincere thanks to Prof. Emer. Tohru Uamida and Prof. Mayumi Yamada, Hokkaido University, for their kind guidance and encouragement.

\section{Metamorphosis of Medusae}

1) The youngest medusae

The youngest medusae so far found in the plankton had four perradial marginal tentacles and four small conical rudiments of interradial marginal tentacles. Twentyone specimens of this stage were collected from April to early May. Four of them showed the earliest phase (Fig. 1). The umbrella is bell-shaped, slightly higher

Publ. Seto Mar. Biol. Lab., XVIII (1), 21-35, 1970. (Article 2) 
than wide, being 2.1-3.0 mm high and 1.8-2.4 mm wide. There are conspicuous exumbrellar nematocysts regularly confined to three to six patches in each adradius. Each patch consists of 10-60 nematocysts. These exumbrellar nematocysts are characteristic of the young medusae. The jelly is rather thick. The velum is moderately broad. The stomach is tubular and four-sided, about half the length of the subumbrellar height. The peduncle is not yet developed. The mouth is simple, four-sided. There is no swelling of gonadal rudiment. The radial canal is broad and nearly smooth, without any side branches. The ring canal is broad and

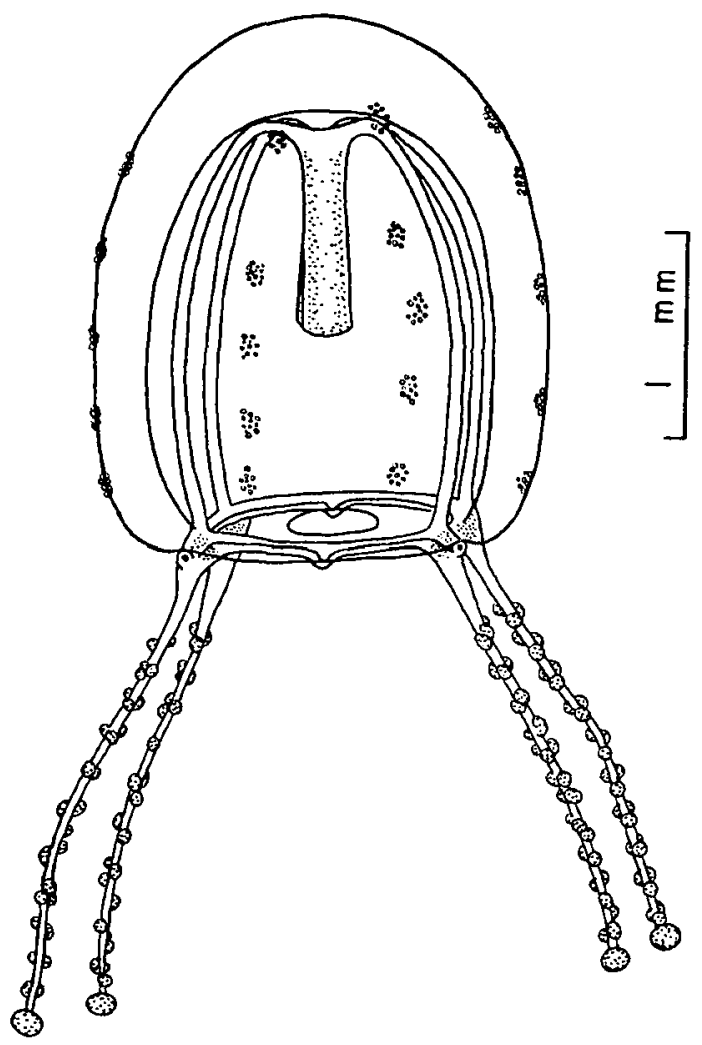

Fig. 1. The youngest medusa of Polyorchis karafutoensis.

simple, with no centripetal canals. There are four perradial marginal tentacles on which 40-50 rather large nematocyst clusters are irregularly scattered. The terminal knob is rather large. The tentacles are hollow and reach nearly the umbrellar height when fully extended. The rudiments of the interradial tentacles are observed as small conical protrusions. The tentacle bulb is short and tubular in shape, and is continued slightly upward over the exumbrellar surface as a spur, on the abaxial side of which there is an ocellus. The stomach, the ring canal and the tentacles are 
pale yellow orange, the radial canals are pale or light orange and the ocelli are dark reddish brown.

Other specimens of this stage developed further in some points such as increasing of size, jagging of radial canals, swelling of gonadal rudiments and development of lips and others. Later on, these changes will be described in some details.

\section{2) Development of marginal tentacles}

As described above the youngest medusa had four perradial marginal tentacles and four small conical rudiments of interradial tentacles. The first cycle of marginal tentacles is perradial tentacles and the second is interradial ones. The third cycle is eight adradial tentacles which do not appear precisely on the adradii but slightly

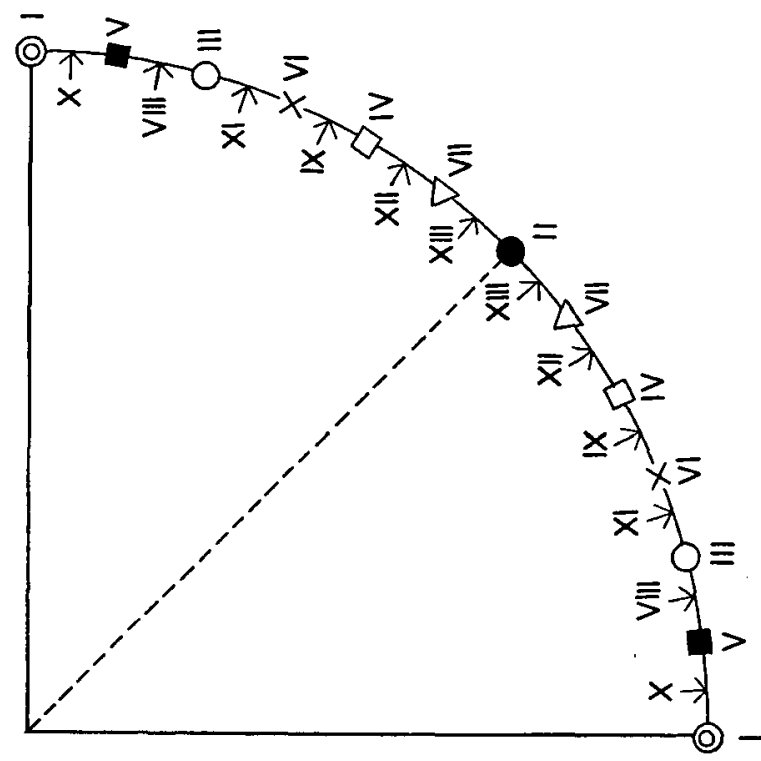

Fig. 2. Diagram showing the sequence of appearances of tentacles in a quadrant.

nearer to the perradii as seen in Ostroumovia horii (UCHIDA and NAGAO, 1959). In the early stage of the third cycle the ratio of the length of the first, the second and the third tentacles is about 5:3:1. In the following stages the marginal tentacles increase in number one by one in each octant in the definite sequence as shown in Fig. 2. The total number of them in each cycle is as follows: 4 (I), 8(II), 16(III), 24(IV), 32(V), 40(VI), 48(VII), 56(VIII), 64(IX), 72(X), 80(XI), 88(XII), 96 (XIII), .... The 13th or further cycles are observed in some old medusae. Till the eighth cycle the tentacles appear in completely fixed sequence. In further cycles, however, there are often found some deviations from the normal sequence such as reversal of the normal order in the successive tentacles and isochronous developments in some octants. The sequence of the development of the tentacles of Polyorchis karafutoensis agrees closely with that of $P$. montereyensis reported by SKOGSBERG (1948). 

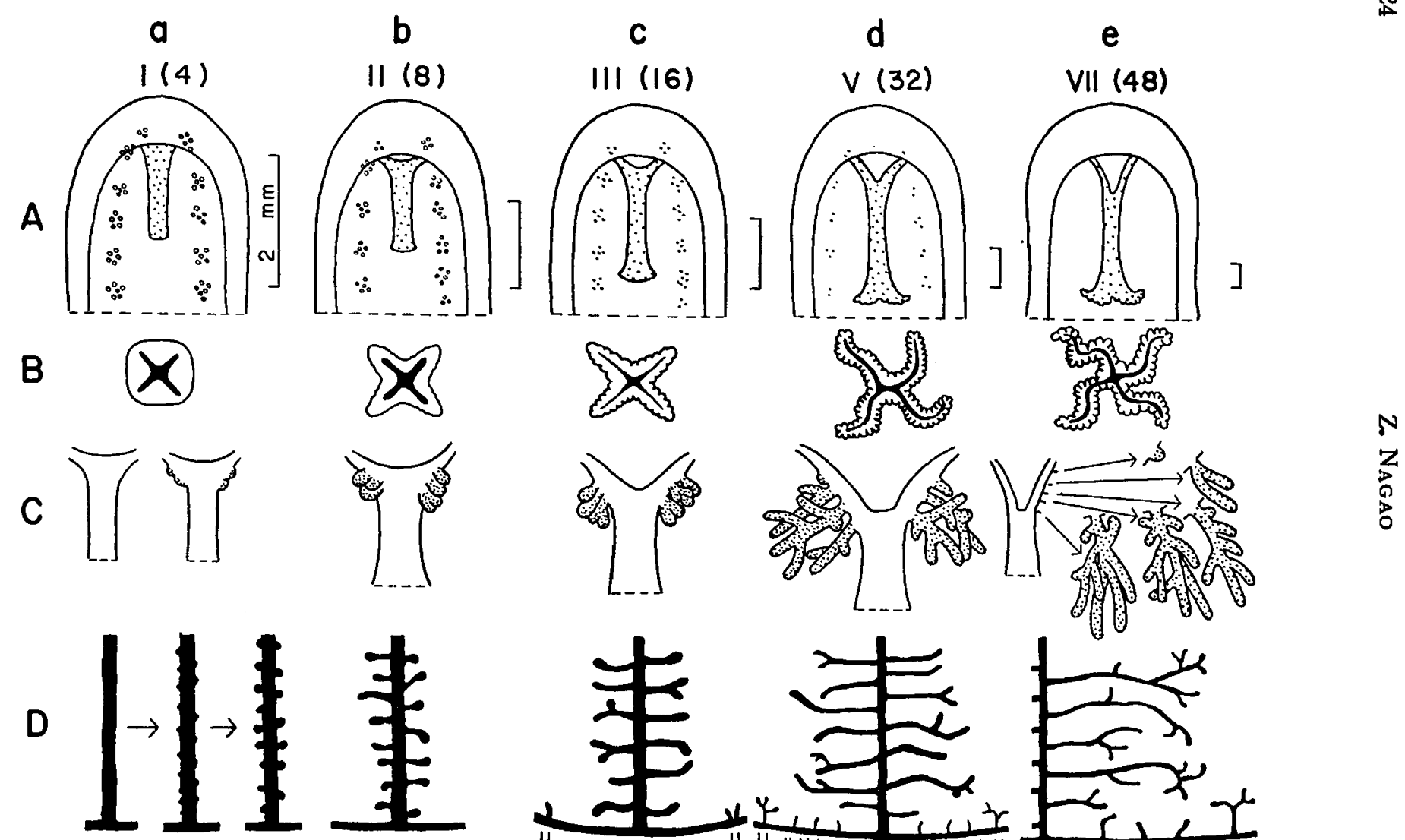

Fig. 3. Successive changes of umbrella and manubrium (A), oral lip (B), gonads (C), and side branches of radial canals and centripetal canals from ring canal (D). 
pale yellow orange, the radial canals are pale or light orange and the ocelli are dark reddish brown.

Other specimens of this stage developed further in some points such as increasing of size, jagging of radial canals, swelling of gonadal rudiments and development of lips and others. Later on, these changes will be described in some details.

2) Development of marginal tentacles

As described above the youngest medusa had four perradial marginal tentacles and four small conical rudiments of interradial tentacles. The first cycle of marginal tentacles is perradial tentacles and the second is interradial ones. The third cycle is eight adradial tentacles which do not appear precisely on the adradii but slightly

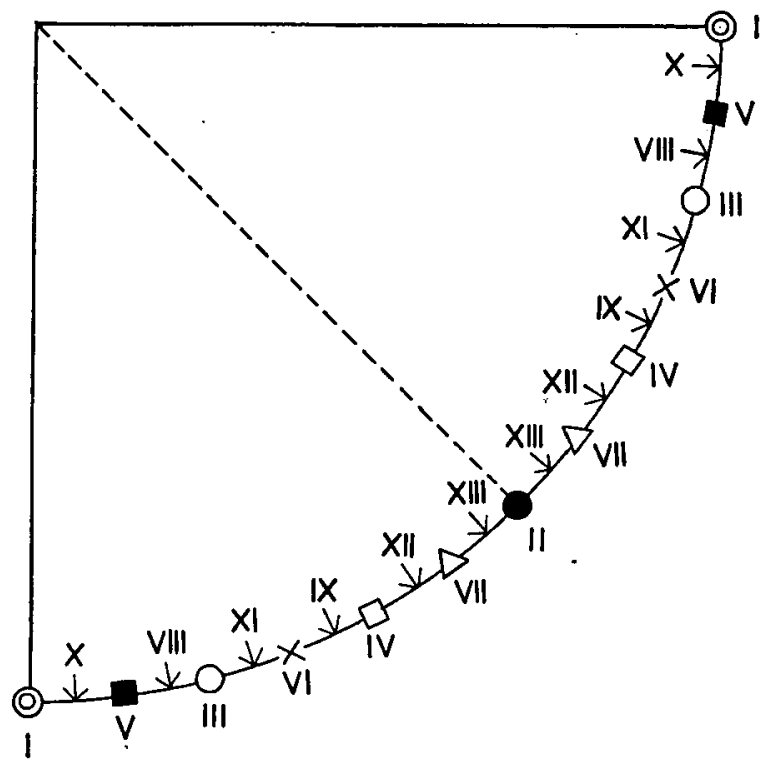

Fig. 2. Diagram showing the sequence of appearances of tentacles in a quadrant.

nearer to the perradii as seen in Ostroumovia horii (UcHIDA and NAGAO, 1959). In the early stage of the third cycle the ratio of the length of the first, the second and the third tentacles is about $5: 3: 1$. In the following stages the marginal tentacles increase in number one by one in each octant in the definite sequence as shown in Fig. 2. The total number of them in each cycle is as follows: $4(\mathrm{I}), 8(\mathrm{II}), 16(\mathrm{III})$, 24(IV), 32(V), 40(VI), 48(VII), 56(VIII), 64(IX), 72(X), 80(XI), 88(XII), 96 (XIII), .... The 13th or further cycles are observed in some old medusae. Till the eighth cycle the tentacles appear in completely fixed sequence. In further cycles, however, there are often found some deviations from the normal sequence such as reversal of the normal order in the successive tentacles and isochronous developments in some octants. The sequence of the development of the tentacles of Polyorchis karafutoensis agrees closely with that of $P$. montereyensis reported by SkoGSBERG (1948). 


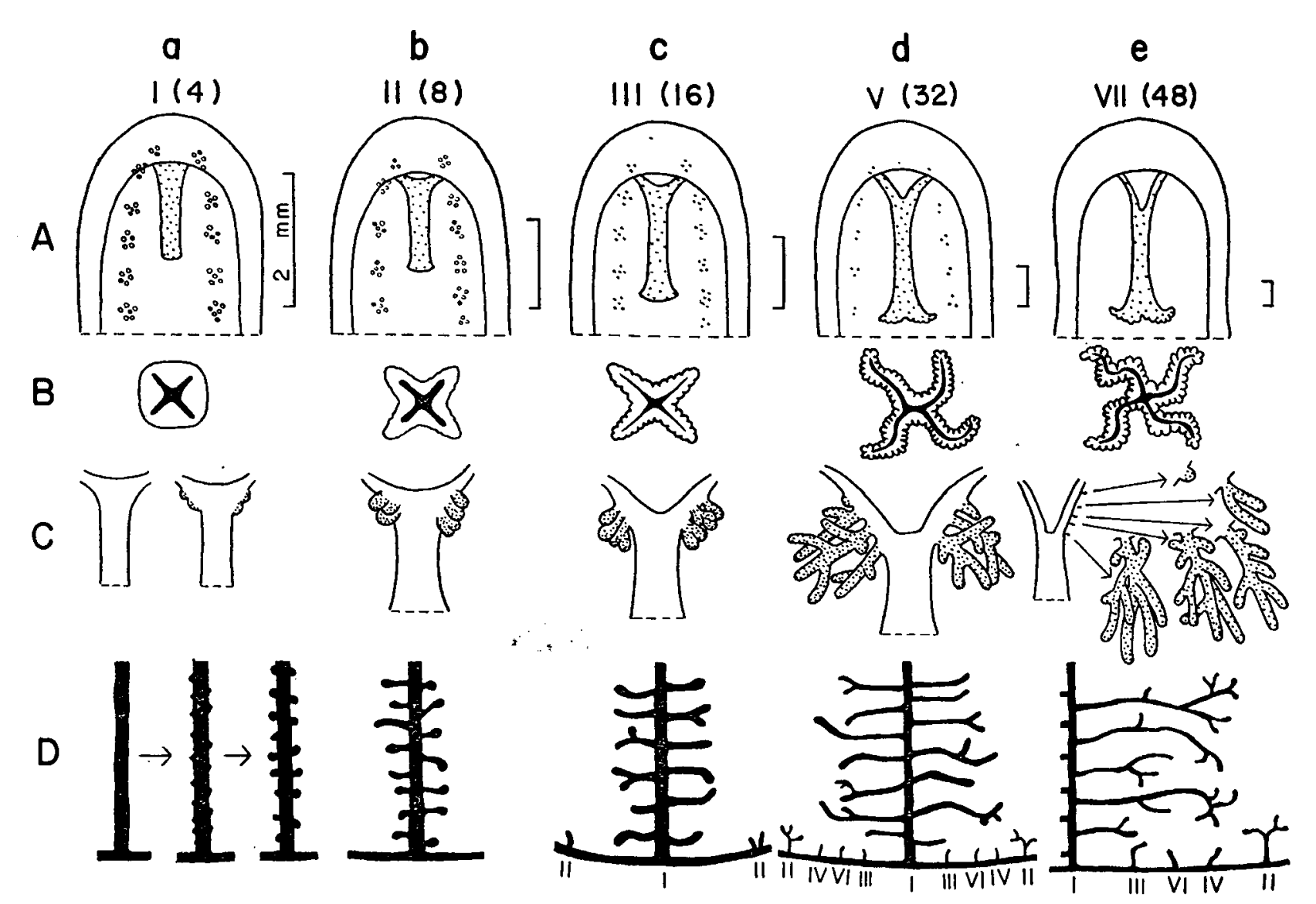

Fig. 3. Successive changes of umbrella and manubrium (A), oral lip (B), gonads (C), and side branches of radial canals and centripetal canals from ring canal (D). 
In the following sections developmental changes will be described using the sequence of the development of the marginal tentacles described above as an index. While foregoing tentacles are growing the tentacles of the next cycle begin to develop, so that specimens are admitted to the stage of the next cycle when the tentacles of the next cycle become equipped with several nematocyst clusters and ocelli come to appear distinctly on their bulbs.

\section{3) Umbrella}

As described above the umbrella of the youngest medusa is $2.1 \mathrm{~mm}$ high and 1.8 $\mathrm{mm}$ wide in the minimum size. When fully grown it becomes $50 \mathrm{~mm}$ high and $43 \mathrm{~mm}$ wide in the maximum size among the present specimens. The umbrella shows little change in its form during growth. The ratio between the height and the width of the umbrella is nearly constant, $1.3(1.1-1.46): 1$ during growth. At V-VII tentacle's stages small apical pockets of subumbrellar cavity are often observed in some specimens. The characteristic exumbrellar nematocysts of the young medusae are the most conspicuous at the first tentacle's stage (Figs. 1, 3 Aa). At the second tentacle's stage they are still clearly visible (Fig. $3 \mathrm{Ab}$ ). After then they become gradually indistinct, and disappear completely at VII tentacle's stage (Figs. 3 Ac-Ae, 4). Such characteristic exumbrellar nematocysts arranged in the adradial lines were also observed in 16 tentacled young medusae of $P$. penicillatus by Fewkes (1889) and in the youngest medusa of Spirocodon saltatrix by UCHIDA (1927).

\section{4) Manubrium}

In the early phase of the first tentacle's stage the manubrium is simple, four-sided tubular in form and is about half the length of subumbrellar height (Fig. 1). It gradually becomes wide in the oral portion, and increases in length, then, it reaches almost to the velar opening at $\mathrm{V}$ tentacle's stage.

In the middle phase of the first tentacle's stage the gastric peduncle begins to develop, and increases gradually in size. It becomes distinctly recognizable at IV tentacle's stage, and assumes a completely developed form at VII tentacle's stage.

In the early phase of the first tentacle's stage the mouth is simple, four-sided (Fig. $3 \mathrm{Ba}$ ). The surface of the lip becomes slightly uneven in the later phase of this stage and begins to crenulate at the second tentacle's stage (Fig. $3 \mathrm{Bb}$ ). At the third tentacle's stage perradial corners of the lip begin to spread outside (Fig. $3 \mathrm{Bc}$ ). After this both the extension of the perradial corners and the crenulation of the lip become more conspicuous and each perradial portion of the lip begins to fold one to three times (Fig. $3 \mathrm{Bd}$ ). Thus the complete lip with crenulated margin and with two to three or more foldings is formed at VII tentacle's stage (Fig. $3 \mathrm{Be}$ ).

5) Radial canal and its side branches

As described above the radial canals of the youngest medusa are nearly smooth (Fig. 1). In the next phase of the first tentacle's stage the radial canals become jagged, then respective jags grow outside and swell at the tip, and develop into knob- 
like protrusions at the end of the first tentacle's stage or the beginning of the second tentacle's stage (Fig. $3 \mathrm{Da}$ ). At the second tentacle's stage the side protrusions elongate and each assumes a club-shape (Fig. $3 \mathrm{Db}$ ). Some of them begin to bifurcate distally at the end of this stage or at the beginning of the third tentacle's stage.

At the third tentacle's stage the side branches grow longer and often bend upward or downward and bifurcate in the terminal portion (Fig. $3 \mathrm{Dc}$ ). In some specimens one or two small secondary branches begin to appear from respective side branches. The side branches elongate further and draw near those issued from the adjoining radial canals. The bendings become complicated further and the secondary branches increase in number (Fig. $3 \mathrm{Dd}, \mathrm{De}$ ). After $\mathrm{X}$ tentacle's stage the side branches with many complicated further branches are increasingly observed. There are two types of the branching mode of side branches; in one type the main stem is rather simple giving off some secondary branches only in its terminal portion, while in the other type the main stem bends complicatedly giving rise to rather many short further branches.

The side branches are nearly constant in number irrespective of age as pointed out by Uchida (1927), usually 20-31 (minimum 17, maximum 50). The difference of the number of side branches among four radial canals within a single medusa is 3 to 12 and that between two sides of each canal is mostly 0 to 3 , though up to 7 at the maximum. Such variation was observed also in Polyorchis montereyensis by SkogsBerg (1948).

\section{6) Centripetal canals from ring canal}

At the end of the second tentacle's stage or the third tentacle's stage the centripetal canals begin to develop from the ring canal as one to three upward and conical growths at each interradial position (Fig. $3 \mathrm{Dc}$ ). Of these only one grows rapidly in later stages, while the rest remain short. At the end of the third tentacle's stage or the fourth tentacle's stage next canals appear at the adradial positions and then the interradial canals begin to bifurcate at the tip. After $\mathrm{V}$ tentacle's stage the interradial canals begin to issue several short branches and gradually become arborescent (Figs. $3 \mathrm{Dd}, 5$ ). On the one hand, successive canals begin to arise in the definite sequence of the fourth, sixth and seventh tentacle's positions skipping over the fifth tentacle's one (Fig. $3 \mathrm{Dd}, \mathrm{De}$ ), although there are often observed some deviations from the normal sequence and some developmental lags in some octants. After VII tentacle's stage some of the adradial and successive canals begin to bend slightly, and bifurcate at the tip; the bifurcation occurs only once, rarely twice even in old medusae. On the other hand, the interradial canals continue to branch somewhat dichotomously and there are 2 to 10 branches at VII or VIII tentacle's stage, and after $\mathrm{X}$ tentacle's stage 14 branches are observed at the maximum.

7) Gonads

The first sign of gonadal development appears as slight swellings at the junction 
of the stomach and the radial canals in the middle phase of the first tentacle's stage. Then the young gonads grow into two or three bud-like swellings at the end of this stage or the beginning of the second tentacle's stage (Fig. $3 \mathrm{Ca}$ ), and further begin to elongate, and bifurcate at the end (Fig. $3 \mathrm{Cb}$ ). At the third tentacle's stage they increase to three to five on each perradius, and assume a short tubular form, mostly bifurcating at the end (Figs. $3 \mathrm{Cc}, 4$ ). During IV and V tentacle's stage

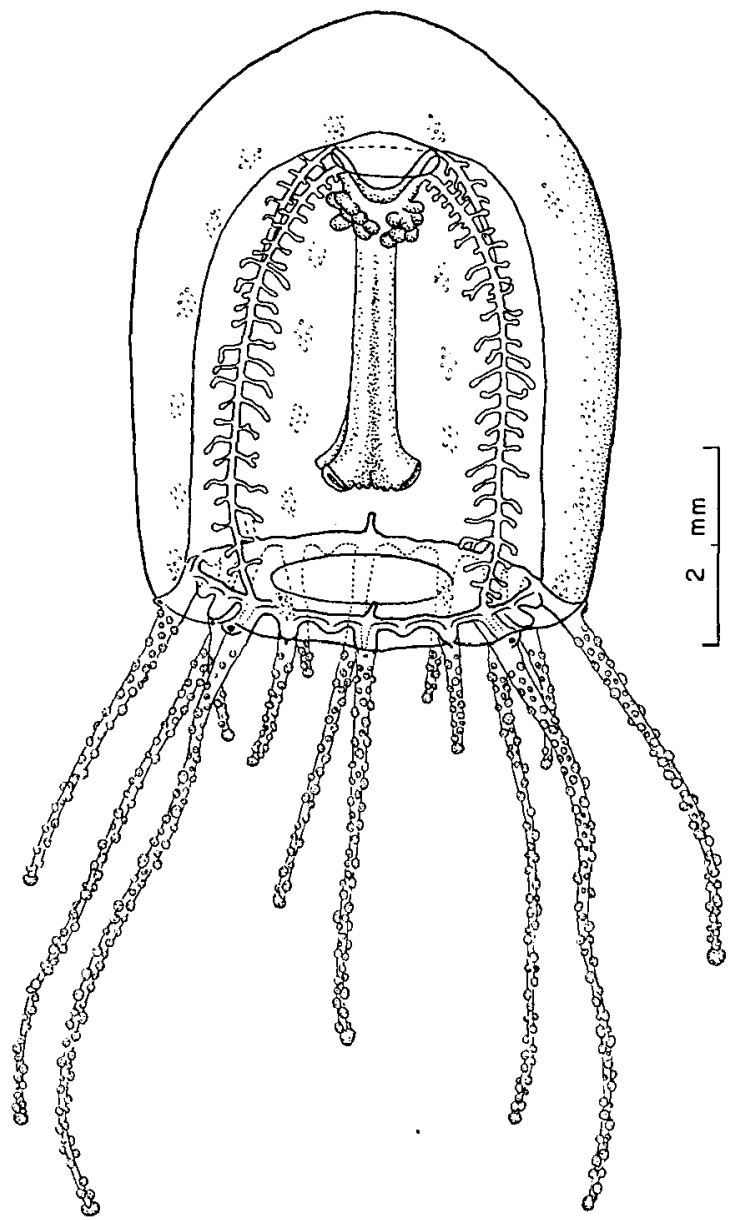

Fig. 4. Young medusa in the third tentacle's (16 tentacles) stage.

the young gonads continue to elongate to assume a banana-like form, each branching several times, somewhat dichotomously but not regularly. Meanwhile several new young gonads are budded from the higher levels above the old gonads. Thus the basic form of the gonad is almost completed, which is composed of three to four or more main stems on each perradial line, each branching three to ten times. The 
main stems located at higher levels are less branched than lower ones; the branching may take place at any level of the stem (Fig. $3 \mathrm{Cd}, \mathrm{Ce}$ ).

The gonads begin to mature after VI tentacle's stage. With maturation the gonads increase rapidly in size till their ends reach almost to the velum. At VIII tentacle's stage they become completely matured; there are three to seven main gonadal stems on each perradial axis, and most of them give rise to 1 to 14 branches. After this the gonads show little changes except a slight increase in length and an addition of a few branches. Medusae after $X$ tentacle's stage are occassionally provided with reduced gonads and are regarded as spent.

\section{8) Tentacle bulb and ocellus}

At the beginning of development when the tentacles grow out directly below the ring canal the tentacle bulbs are not yet differentiated as observed in $P$. penicillatus by Fewkes (1889). As the tentacles grow the tentacle bulbs assume gradually a short tubular form, then they increase gradually in length toward the exumbrellar side, reaching almost $2.0 \mathrm{~mm}$ at the maximum. As a result of the elongation of tentacle bulbs with age tentacles in old medusae are arranged superficially in two or three rows, with shorter ones on the inner side as described by KisHinouye (1910) and Uchida $(1925,1927)$. The ocelli appear on the exumbrellar spurs with the development of several nematocyst clusters on the corresponding young tentacles, and become distinct with age, but the pigment of old ocelli shows a tendency to fade after IX tentacle's stage.

\section{Adult Medusae}

As described above, at VII or VIII tentacle's stage, the medusae mature and most of developmental changes have been completed. As adult medusae of Polyorchis karafutoensis (Fig. 5) were already described by KISHINOUye (1910) and UchidA $(1925,1927)$, here are stated only some points in detail upon specimens after VIII tentacle's stage.

The umbrella is deep bell-shaped, $25-50 \mathrm{~mm}$ in height and 18-45 $\mathrm{mm}$ in width. The average ratio between the height and the width of the umbrella is 1.25: 1. The maximum width is found at about the middle or somewhat nearer to the apex of the umbrella. Uchida (1925) reported an extremely large specimen (105 $\mathrm{mm}$ high and $100 \mathrm{~mm}$ wide) of this species. So far as the author observed, medusae more than $50 \mathrm{~mm}$ high are rare and the largest medusa ever observed was $67 \mathrm{~mm}$ high and $60 \mathrm{~mm}$ wide, which was collected on August 15, 1967 in Akkeshi Bay.

The jelly is thick at the apical portion, and becomes thinner toward the umbrellar margin. The gastric peduncle is conical, and occupies about $1 / 3$ of the total length of the manubrium. The stomach is long, four-sided, and tubular, widening toward the mouth. It reaches almost to the velar opening. The mouth is nearly cruciform and is expanded to form four frilled lips, respectively in each perradius, which are 
folded two or three times. The radial canal is moderate in thickness, and has 20-31 side branches on either side. These side branches run almost horizontally and, near the end, often bend up and down giving rise to several secondary branches which are often subdivided further. The side branches are better developed at the middle or in the lower part of the radial canal, but short and thinner near the gastric peduncle.

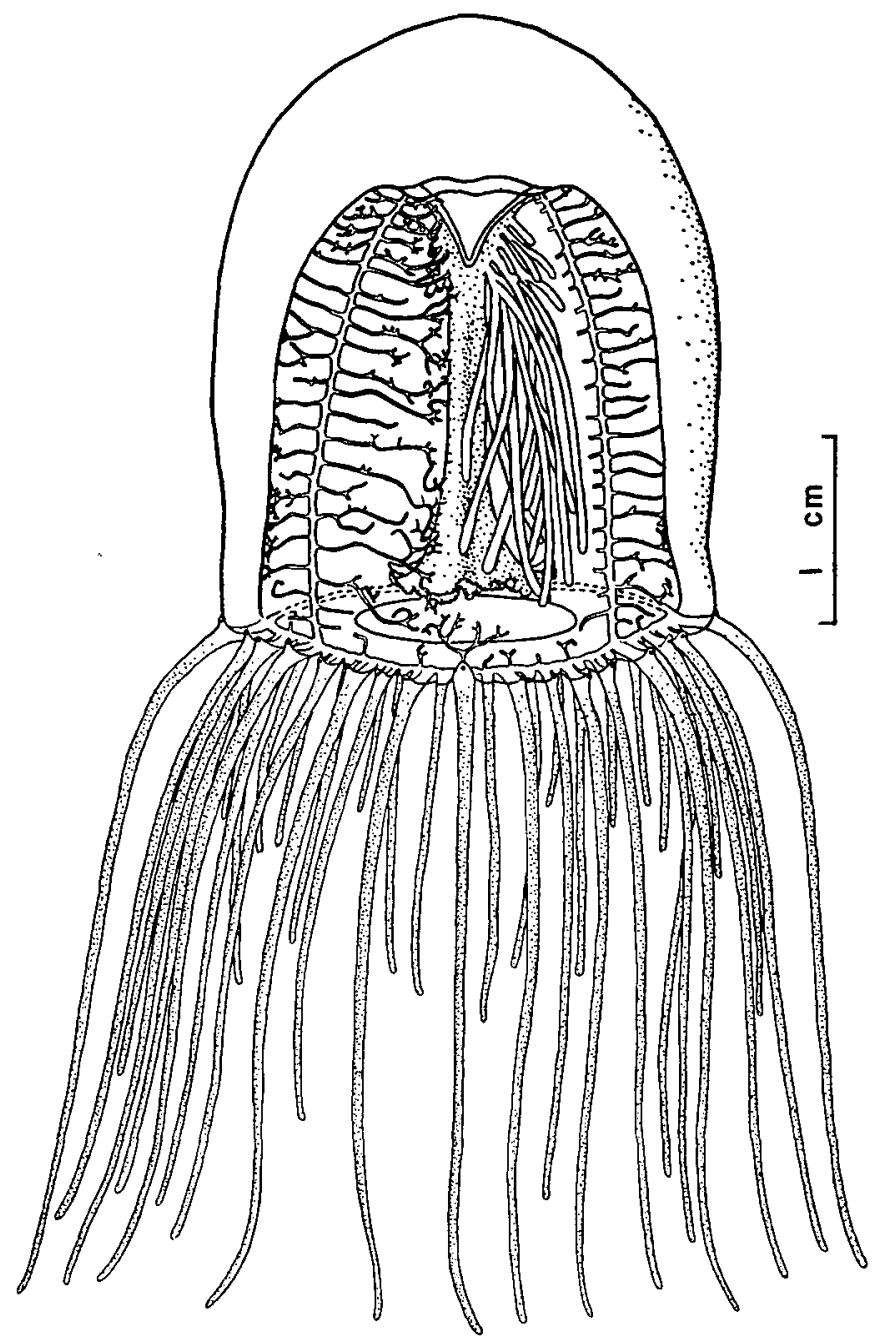

Fig. 5. Adult medusa in XI tentacle's (80 tentacles) stage.

There are roughly two types of the side branches. In the first type the side branches run nearly straight, sometimes giving rise to $1-3$ secondary. branches in the middle portion, and mostly sending out 1-9 further branches in the terminal portion, which are often bending and ending in a somewhat thicker tip. In the second type the 
side branches are more or less bending in the distal portion, more than half of them send out 1-3 secondary branches in the middle portion, and most of them are divided in the terminal portion somewhat dichotomously, generally 1-9 times (29 times at the maximum). Thus the space between the terminals of the well developed side branches from the facing sides of each pair of radial canals is very narrowed and only $1 / 6-1 / 10$ as wide as the span between the radial canals.

The ring canal is narrow and straight, giving rise to the centripetal canals at II-VII tentacle's positions but V tentacle's position. The centripetal canal at the interradial position is best developed and arborescent, but those at other positions are usually simple.

The marginal tentacles arise from the whole bell margin, increasing in number eight by eight as described above, and attaining 96 or more in old medusae. Many rather large nematocyst clusters are irregularly scattered on the tentacles. There is an ocellus on the spur of the tentacle bulbs.

The gonads are tubular, hanging down from the middle and lower portions of the gastric peduncle and the highest end of the stomach on each perradius. They reach almost to the velum. On each perradius there are three to seven main stems of the gonad, most of them branching dichotomously 1 to 14 times, in many cases in the proximal half of the stem. In the result, 12 to 55 (28 on an average) tubular gonads are observed on each perradius.

There are two colour types, the canals and the gonads are tinted in the one type with pale orange, but with pale yellow in the other type. In medusae of the former type the radial canals and the ring canal are pale yellow orange and the stomach, gonads and the tentacles are yellowish orange or pale yellow-orange. In medusae of the latter type, however, the stomach, radial and ring canals, gonads and the tentacles are pale yellow or yellowish gray. The ocellus is dark reddish brown in both types. Such coloration becomes paler with age.

The adult medusae were often found parasitized by larvae of a pycnogonid, Ammothea alaskensis as already reported by Uchida $(1927,1940)$ and Okuda $(1940)$.

\section{Nematocysts}

The medusae have three kinds of nematocysts (Figs. 6-11): stenoteles, desmonemes and microbasic mastigophores. The exumbrellar nematocysts which are characteristic of the young stage consist of the microbasic mastigophores only, while other parts of medusae have two kinds of nematocysts: stenoteles and desmonemes. The butt of some microbasic mastigophores shows a tendency to become slightly wider at the terminal end. The size (length $\times$ width) of capsules is as follows.

Stenoteles (undischarged): 17-25 $\mu$ (average, 19.6) $\times 13-19 \mu$ (average, 14.8). Desmonemes (undischarged): 11-17 $\mu$ (average, 13.8) $\times 5-7.5 \mu$ (average, $6.0)$. 
Microbasic mastigophores (undischarged): Solely as elements of exumbrellar nematocysts of young medusae. 22-31 $\mu$ (average, 26.8) $\times 12-18 \mu$ (average, 15.6).

G.O. Magkie and G.V. Magkie (1963) described two kinds of nematocysts, stenoteles and desmonemes in $P$. penicillatus. The presence of stenoteles and desmonemes in the genus Polyorchis suggests that the genus Polyorchis belongs to the Capitata from the view of the distribution of the nematocysts among the athecate-

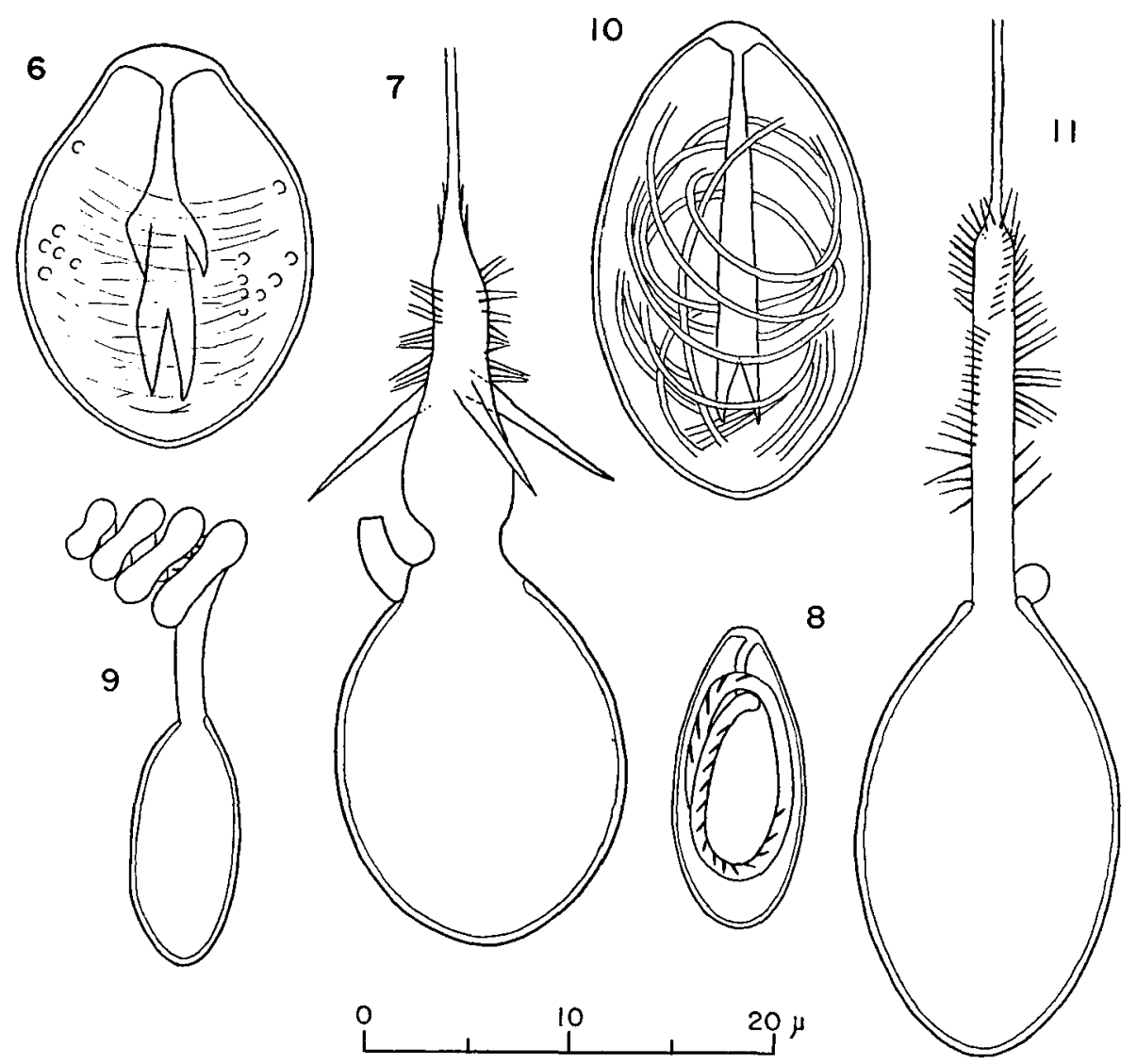

Figs. 6-11. Nematocysts. 6, 7. Stenoteles. 8, 9. Desmonemes. 10, 11. Microbasic mastigophores.

anthomedusan hydroids as in the case of Spirocodon saltatrix shown by Irô and INOUE (1962). Moreover, the existence of microbasic mastigophores on the exumbrella of the young medusae is common to $P$. karafutoensis and Sarsia tubulosa as reported by the author (NAGAO, 1969). This fact and the similarity of the kinds of nematocysts between the above-mentioned two medusae suggest seemingly some phylogenetic affinity between the two genera as already pointed out by the author (1969). 


\section{Growth and Seasonal Occurrence}

The size of the umbrella in respective tentacle's stages is shown in Table 1. The height and the width of the umbrella increase rapidly with the stages up to XI tentacle's stage, thus the growth continues after VII tentacle's stage when the medusae assume the adult form and mature.

Table 1. Size of the umbrella of Polyorchis karafutoensis at each tentacle's stage in mm. Figures in parentheses after Roman stage number show the number of tentacles and those in columns of height and width show the average value.

\begin{tabular}{|l||c|c|c|c|}
\hline Stage & I (4) & II (8) & III (16) & IV (24) \\
\hline Height & $2.1-4.4(3.5)$ & $4.4-5.4(4.8)$ & $4.4-9.2(6.5)$ & $9.8-14(11)$ \\
\hline Width & $1.8-3.4(2.4)$ & $3.3-4.1(3.7)$ & $3.2-6.3(5.0)$ & $6.3-10(7.8)$ \\
\hline $\begin{array}{l}\text { No. of } \\
\text { specimens }\end{array}$ & 21 & 14 & 23 & 17 \\
\hline
\end{tabular}

\begin{tabular}{|l||c|c|c|c|}
\hline Stage & V (32) & VI (40) & VII (48) & VIII (56) \\
\hline Height & $9.2-15.8(13.1)$ & $13-19(15.5)$ & $12.5-29(19.6)$ & $18-35(26.1)$ \\
\hline Width & $6.0-11.5(9.0)$ & $8.5-15(11.7)$ & $10-25(15.2)$ & $13-32(20.7)$ \\
\hline $\begin{array}{l}\text { No. of } \\
\text { specimens }\end{array}$ & 33 & 31 & 32 & 11 \\
\hline
\end{tabular}

\begin{tabular}{|l||c|c|c|}
\hline Stage & IX (64) & X (72) & XI (80) \\
\hline Height & $23-40.5(30.8)$ & $22-43.5(31.7)$ & $28.5-46(38.5)$ \\
\hline Width & $18-33(25.0)$ & $15.5-33(24.4)$ & $22.5-45(32.8)$ \\
\hline $\begin{array}{l}\text { No. of } \\
\text { specimens }\end{array}$ & 13 & 10 & 3 \\
\hline
\end{tabular}

From middle April to early May in 1963 and 1965, the youngest medusae were found in the plankton in the innermost part of Akkeshi Bay and in Akkeshi Lake. It seems that the young medusae are liberated from the hydroid in March and April because some advanced specimens with developing interradial tentacles were already found in April. The young medusae in the second tentacle's stage were seen from middle April to early June, then followed the medusae from III to VI tentacle's stage in May and June. The medusae in VII tentacle's stage when they assume nearly the adult form occurred after the middle of May. The adult medusae older than VII tentacle's stage appeared simultaneously in middle June, and spawned from middle June to late July. The spent medusae with damaged tentacles increased gradually, but all died out in August. 
In the middle of April, 1965, when the youngest medusae appeared the water temperature of the localities was $1.0^{\circ}-5.2^{\circ} \mathrm{C}$ (average, $2.9^{\circ} \mathrm{C}$ ); it rose gradually to $15.0^{\circ}-18.5^{\circ} \mathrm{C}$ (average, $16.3^{\circ} \mathrm{C}$ ) in early August when most of medusae disappeared. When the adult medusae appeared and started the spawning the water temperature had attained to $10^{\circ} \mathrm{C}$.

\section{Discussion}

So far the following four species belonging to the genus Polyorchis are accepted as valid: $P$. penicillatus (Eschscholtz), $P$. karafutoensis Kishinouye, $P$. haplus Skogsberg and $P$. montereyensis Skogsberg (Kramp, 1961).

The diagnostic characters of the genus Polyorchis are as follows: many side branches of radial canals, centripetal canals from the ring canal, hollow marginal tentacles along the whole bell margin and sausage shaped gonads hanging down from the junction between the manubrium and the radial canals.

In most specimens of $P$. haplus the radial canals are nearly simple (SkogsBerg, 1948), this state corresponds to the first tentacle's stage in $P$. karafutoensis. In $P$. penicillatus the side branches from the radial canals are short, more or less knoblike in shape, but often issuing 1-4 secondary branches (Little, 1914; Skogsberg, 1948). The state of these branches remains at the step of the second or third tentacle's stage of $P$. karafutoensis. The side branches of old $P$. montereyensis often irregularly bend and send out 1-4 short irregular secondary branches (SKOGsBerg, 1948), this state of branchings corresponds to $\mathrm{V}$ tentacle's stage of $P$. karafutoensis. Next, any signs of the centripetal canals are not seen on the ring canal in $P$. haplus. In $P$. penicillatus and $P$. montereyensis knob-like canals are found growing out from the ring canal, even some signs of branching are shown in the latter species (SKogsBerg, 1948). In contrast with three species mentioned above $P$. karafutoensis has the most highly developed centripetal canals. In $P$. haplus and $P$. penicillatus, the gonads bifurcate rarely and in $P$. montereyensis they usually have each only one branch. In $P$. karafutoensis, however, the branching of the gonads occurs commonly and most gonads give rise to $1-14$ branches as described above. From the developmental grades of the diagnostic characters mentioned above the following evolutional line in the genus Polyorchis, haplus-penicillatus-montereyensis-karafutoensis, seems very likely. $P$. haplus remains at the lowest level of the line, while $P$. karafutoensis stands at the highest level.

In the genera Polyorchis and Spirocodon the following characters are common in adult medusae: well developed gastric peduncle and frilled oral lip, many blind side branches from the radial canals and centripetal canals from the ring canal. Moreover, the developmental changes from young to adult in Polyorchis described above resemble those in Spirocodon reported by UchidA (1927). The youngest medusae of both genera are similar to Sarsia; the characteristic distribution of the exumbrellar 
nematocysts in the young medusae of Polyorchis is also observed in the youngest medusa of Spirocodon (Uchida, 1927). However, the shape of gonads and the arrangement of tentacles are distinctly differ from each other in these two genera. Further, the kinds of nematocysts differ somewhat from each other. The medusae of Polyorchis have stenoteles, desmonemes and microbasic mastigophores, the last of which are found only on the exumbrella of the young medusae. The medusae of Spirocodon, however, have stenoteles, desmonemes and microbasic euryteles (ITô and INOUE, 1962). Judging from the above mentioned comparison it is probable that both Polyorchis and Spirocodon are derived from the common Sarsia-like ancestor and have differentiated along a special line which is characterized by several characters common to both genera, but respectively in somewhat different directions.

\section{Summary}

1) The metamorphosis from young to adult in the medusan stage of Polyorchis karafutoensis is described.

2) The youngest medusae captured, 2-3 mm high, have four perradial tentacles, four-sided tubular stomach, four simple radial canals and exumbrellar nematocysts on the adradii.

3) The tentacles increase in number with growth in each octant in the definite sequence. The side branches from the radial canals start as knob-like protrusions, then grow longer, bend in some ways, and repeat branching several times. The centripetal canals from the ring canal originate on the interradii and increase in number in the definite sequence. The gonads are formed first as several swellings at the base of manubrium, then increase in number and length and branch several times. Through such processes the medusae assume the adult form at VIII tentacle's stage, and attain maturity.

4) In Akkeshi Bay the youngest medusae appear in April. The spawning takes place from middle June to late July, and spent medusae mostly die out in August.

5) On the developmental details the systematic relations were discussed among the species of the genus Polyorchis and between the genera Polyorchis and Spirocodon.

\section{REFERENCES}

Fewkes, J.W. 1889. New Invertebrata from the coast of California. Bull. Essex Inst., 21 : 99-142, Pls. $1-7$.

Foerster, R.E. 1923. The hydromedusae of the west coast of North America, with special reference to those of the Vancouver Island region. Contr. Canad. Biol. Fish. N.S., 1: 219-277, 5 pls.

ITO, T. and K. INoue 1962. Systematic studies on the nematocysts of Cnidaria. I. Nematocysts of Gymnoblastea and Calyptoblastea. Mem. Ehime Univ. Sect. II. Ser. B., 4: 445-460. PIs. V-IX.

Kishinouye, K. 1910. Some medusae of Japanese waters. J. Coll. Sci. Tokyo, 27: 1-35, 5 pls.

Kramp, P.L. 1961. Synopsis of the medusae of the world. J. Mar. Biol. Ass. U. K., 40: 1-469. 
LrTtle, E.V. 1914. The structure of the ocelli of Polyorchis penicillata. Univ. California Publ., 11: 307328, Pls. 13-15.

Mackie, G.O. and G.V. Mackie 1963. Systematic and biological notes on living hydromedusae from Puget Sound. Nat. Mus. Canada Bull., 199: 63-84.

NAGAo, Z. 1963. The early development of the anthomedusa, Polyorchis karafutoensis KishinouYE. Annot. Zool. Japan., 36: 187-193.

1969. The nematocysts and the life cycles of some hydromedusae. (In Japanese, with English abstract.) Proc. Jap. Soc. Syst. Zool., 5: 37-41.

OKudA, S. 1940. Metamorphosis of a pycnogonid parasitic in a hydromedusa. J. Fac. Sci. Hokkaido Imp. Univ. Ser. VI, Zool., 7: 73-86.

Skogsberg, T. 1948. Systematic study of the family Polyorchidae (Hydromedusae). Proc. Calif. Acad. Sci., 26: 101-124.

UchidA, T. 1925. Some hydromedusae from northern Japan. Jap. J. Zool., 1: 77-100.

- 1927. Studies on Japanese hydromedusae 1. Anthomedusae. J. Fac. Sci. Imp. Univ. Tokyo, Sect. IV Zool., 1 : 145-241, Pls. X, XI.

1940. The fauna of Akkeshi Bay. XI. Medusae. J. Fac. Sci. Hokkaido Imp. Univ. Ser. VI, Zool., $7:$ :277-297.

Uchida, T. and Z. Nagao 1959. The life-history of a Japanese brackish-water hydroid, Osiroumovia horii. J. Fac. Sci. Hokkaido Univ., Ser. VI, Zool., 14: 265-281.

Uchida, T., M. Yamada, F. Iwata, C. Oguro and Z. Nagao 1963. The zoological environs of the Akkeshi Marine Biological Station. Publ. Akkeshi Mar. Biol. Stat., No. 13, 36 pp. 4 pls. 